\title{
Application of SPC in Short Run and Small Mixed Batch Production: Case of Bakery Equipment Producer
}

\author{
DOI: 10.12776/QIP.V22I3.1174
}

\author{
Darina Juhászová \\ Received: 08 October 2018 Accepted: 26 November 2018 Published: 30 November 2018
}

\begin{abstract}
Purpose: The purpose of this paper is to present preliminary research in statistical process control (SPC) of short run and small mixed batches (SR-SMB) at the organization producing bakery equipment.

Methodology/Approach: The starting point of the research is a literary survey of possibilities of using SPC for SR-SMB and analysis of the current state of production in a particular organization. Through Pareto analysis, verifying the normality of the data obtained during eleven months, calculation of process capability and performance it was possible to prepare control charts. Finally, the single-case study shows that the proposed control charts are applicable in a small batch and mixed production in the organization producing bakery equipment.
\end{abstract}

Findings: Through SPC implementation in bakery equipment SR-SMB production it is possible to understand the behaviour of the process and to organize better and control the production of expensive precision components.

Research Limitation/implication: Limitation of the research is that data have not been reviewed by individual machines and the impact of individual machines and their settings is not displayed separately.

Originality/Value of paper: Using SPC in the bakery equipment industry is far from common practice. The article presents the first part of the research, which is the starting point for more detailed analysis needed to optimize the use of materials, energy and environmental consequences.

Category: Case study

Keywords: bakery equipment; control chart; short run; small mixed batch; SPC; $\mathrm{X}_{\mathrm{i}}$ diagram; $\mathrm{mR}$ diagram; $\overline{\mathrm{X}}, \mathrm{R}$ diagram; Hotelling $\mathrm{T} 2$ diagram 


\section{INTRODUCTION}

The competitive pressure on the continuous improvement of organizations' performance in the current, ever-changing environment is very high. The business environment increases the need for versatility and flexibility of production in highly efficient production systems. These systems do not need to have material on stock but require products, respectively their components, to receive and deliver "just-in-time" in "Lean" organizations (Brännmark et al., 2012).

Therefore, organizations must be able to produce a broader range of products in smaller batches and shorter production cycles. Production systems need to be flexible, ready for adjustments, prepared to change, and change the changes.

The opportunity for research is in a less explored and literally-documented field that focuses on short-run (SR) processes and small mixed batches (SMB) in the bakery equipment industry. This industry is characterized by its high requirements for material safety and precision components and products.

Consequently, the implementation of statistical process control (SPC) must focus on critical manufacturing processes of such products.

The presented research is going through preparation for the dissertation thesis and is divided into several phases. In the first phase, the current state of the organization was examined regarding production organization and production control, quality assurance and conceptual research framework according to (Juhászová and Zgodavová, 2017; Juhászová and Čička, 2018). The second phase aimed at problem definition and determining performance metrics. The third, analytical phase presented in this article, after identification, validation and selecting the causes using Pareto analysis aims to create control charts for SRSMB SPC.

Phases of improvement and design of a new management method will be gradually solved in the next stage of research.

\section{RESEARCH PROBLEM AND OBJECTIVES}

Products that are generated by one or more similar processes are usually considered as different entities. As a result, organizations often focus on the product and analyze the sources of process changes. Due to the fact, that in short production cycles with a small number of identical products it is not possible to obtain sufficient information for management (quality management, logistics or financial management), it is necessary to focus on the common element, and that is the process itself.

Based on best practices for the application of control charts for processes with long production cycles and a single product characteristic, it is generally recommended that at least 25 subgroups of data be gathered, and these data can 
be used to create the basis for the control chart (ISO, 2017). In the case of small mixed batch production, many subgroups cannot be created and therefore processes need to be grouped in a predetermined way.

The goal of this research phase is to use Lean Six Sigma analytical tools for taking decisions in the bakery equipment organization about pros and cons of introducing SPC in a small batch and mixed production and to testing it under specific conditions. Control charts for univariate measurement processes were presented in (Juhászová and Zgodavová, 2017; Juhászová and Čička, 2018). Therefore only short summaries will be given in this paper. Control charts for multivariate will be described in detail.

\section{LITERATURE REVIEW AND THEORETICAL FRAMEWORK}

Bakery production lines and equipment are based on the customer's requirements for the final product, which is the bakery dough. Equipment that prepares and modifies the dough is called bread and rolls equipment, dough processing equipment, pizza product equipment. Production of such equipment represents a precision engineering, in some cases, it is a mechatronic production that meets strict standards to produce equipment used in the food industry. Components that come into direct contact with the dough are made of high-quality stainless steel and food grade material.

Research in the field of short run and small mixed batches was in the past mainly focused on products and less on processes, so SPC implementation was related mainly to products. In literary sources and professional practice, by the end of the last century most of the terms "piece production" and "small batch production" were used and were mainly characterized by the number of pieces produced in a batch (Zgodavová, 1995). Examples are in publications (Cullen, 1987; Nuget, 1990) where the following terms can be found: "one-off and small batch production" and (Zgodavová, 1995) "small batch and piece production".

Nowadays, when there are a growing need for the possibility of modifying production according to individual specifications and customer preferences and "Lean" (Brännmark et al., 2012; Jarošová and Noskievičová, 2015) and "Agile Manufacturing" (Lee and Lau, 1999) paradigms, organizations need to focus on SPC to improve processes. This leads to the need to better characterize such production based on cycle time (Tošenovský, 2010) and control time (Zgodavová, 1995) to identify planned and actual production time about a certain number of pieces produced and to provide corrective actions.

According to ISO 7870-8 (2017), the term "short run" (SR) means that only a few pieces are produced, and consequently a different part or item (characteristic) is going will be produced. It means that the production cycle is very short, the repeatability of the production batch is low, and a very small volume of items is in a batch. 
The term "small mixed batch" is used when different products are in the batch, but according to some characteristics they can be investigated together (Zgodavová, 1995).

Based on a more detailed survey (ISO, 2017; Zgodavová, 1995; Cullen, 1987; Jarošová and Noskievičová, 2015; Foster, 1988) for short production cycles and small mixed batches, the following situations can be considered: (a) a small quantity of the same product in a batch; (b) one production process is used when producing different products; (c) several operators use the same machines or devices; (d) lack of parts in one production process to create and maintain process control limits; (e) it is not possible to obtain sufficient data due to a short production cycle; (f) a large volume of different parts are produced for several different customers.

SPC techniques are applicable in any short-run production in small mixed batches, which are repeatable in any way.

The procedure of identifying and grouping similar characteristics and, if necessary, its modifications can be described according to (ISO, 2017), in three steps:

Step 1: Identification of processes $\rightarrow$ Formalization of processes $\rightarrow$ Determination and evaluation of influencing characteristics.

Step 2: Expert knowledge or analysis of existing data $\rightarrow$ Identification of systematic process influencing $\rightarrow$ Groping of characteristics.

Step 3: Use of control charts $\rightarrow$ Periodic and alarm triggered check of the group $\rightarrow$ Systematic influences $\rightarrow$ In case of a systematic impact, return to step 2 .

Multiple processes can be grouped when the same procedure follows them but with different characteristics such as nominal/target value, tolerance, material, measurement process, production machine, tool, environmental conditions, etc. Characteristics that differ between processes are plotted in the cause and effect diagram together with the appropriate parameter.

If there are no significant differences or these differences are systematic, they can be compensated by transforming the values into a single scale. Then, the characteristics can be grouped, and a standard control chart can be used.

During the application of control charts, a number of data is collected, and an amount of knowledge is acquired about processes. Therefore, it is necessary to regularly verify that the terms of data grouping are still valid. This is particularly true when there are warning signs for which no attributable cause can be found. To flexibly group and reorganize processes, it is essential to record characteristics such as meta-data along with the measured data so that each measured value is associated with a group of processes.

The theoretical framework presented in this paper is about selected tools of Six Sigma, which will be used for analysis in a particular organization producing 
bakery equipment: (1) Normality test; (2) Homogeneity of variances; (3) Measurement Systems Analysis (MSA); (4) Control charts for short run and small mixed batch processes: $X_{i}, m R ; \bar{X}, R$ control charts for univariate data; and multivariate Hotelling T-square (T2) control chart for multivariate data using QI Macros SPC Software for Excel (QI-Macros, 2018).

\section{CASE STUDY}

The company where the research was conducted specializes in developing and delivering innovative solutions for the bakery industry.

The organization has its quality assurance system, which is not ISO 9001 certified. The main products of the company are shafts, rollers, electro-cabinets, hoppers and conveyors, which are assembled to dough processing units, dough thickness reducing units, shaping or dosing units. Almost every project has specific customer requirements and is a so-called "turn-key" solution. Repeatability of production is very low (5 pieces of products are considered to be series), and this predetermines high degree of detail of construction and technological preparation of production as well as the scope of work related to the development of the technological process.

Frequent changes and workplace adjustments place increased demands on time consumption, and work interruptions, high level of work-in-progress is present, and so is an uneven use of production facilities. The following components are included in the overall research: tube, shaft, flange and roller $(400 ; 600,800)$ made of AISI 304 DIN 1.4301. The manufacturing process is as follows:

(1) Cutting raw material in cutting room (vertical separation of seamless tubes to exact length, cutting of round bars).

(2) Advance preparation of individual parts of the roller on lathe machine (flanges, tube, and shaft), axial alignment and turning diameters.

(3) Welding flanges to the shaft, welding tube to the shaft with flanges.

(4) Turning individual shaft diameters, roller diameter concerning the required roughness, circular and total runout tolerances, and straightness (form tolerance).

(5) Milling shaft keyways and shaft threads. Incoming inspection is not performed as a raw material is purchased from certified vendors with an attestation.

Only post-operational control is in place in the plant. Technical Control Department does measurements of selected characteristics of the final products.

The management of the organization has decided to explore the possibilities of optimizing production regarding time consumption, work interruptions, reducing 
the number of work-in-progress processes, use of production facilities and SPC implementation.

Precise bakery equipment process work flow is described in Fig. 1 and Fig. 2.

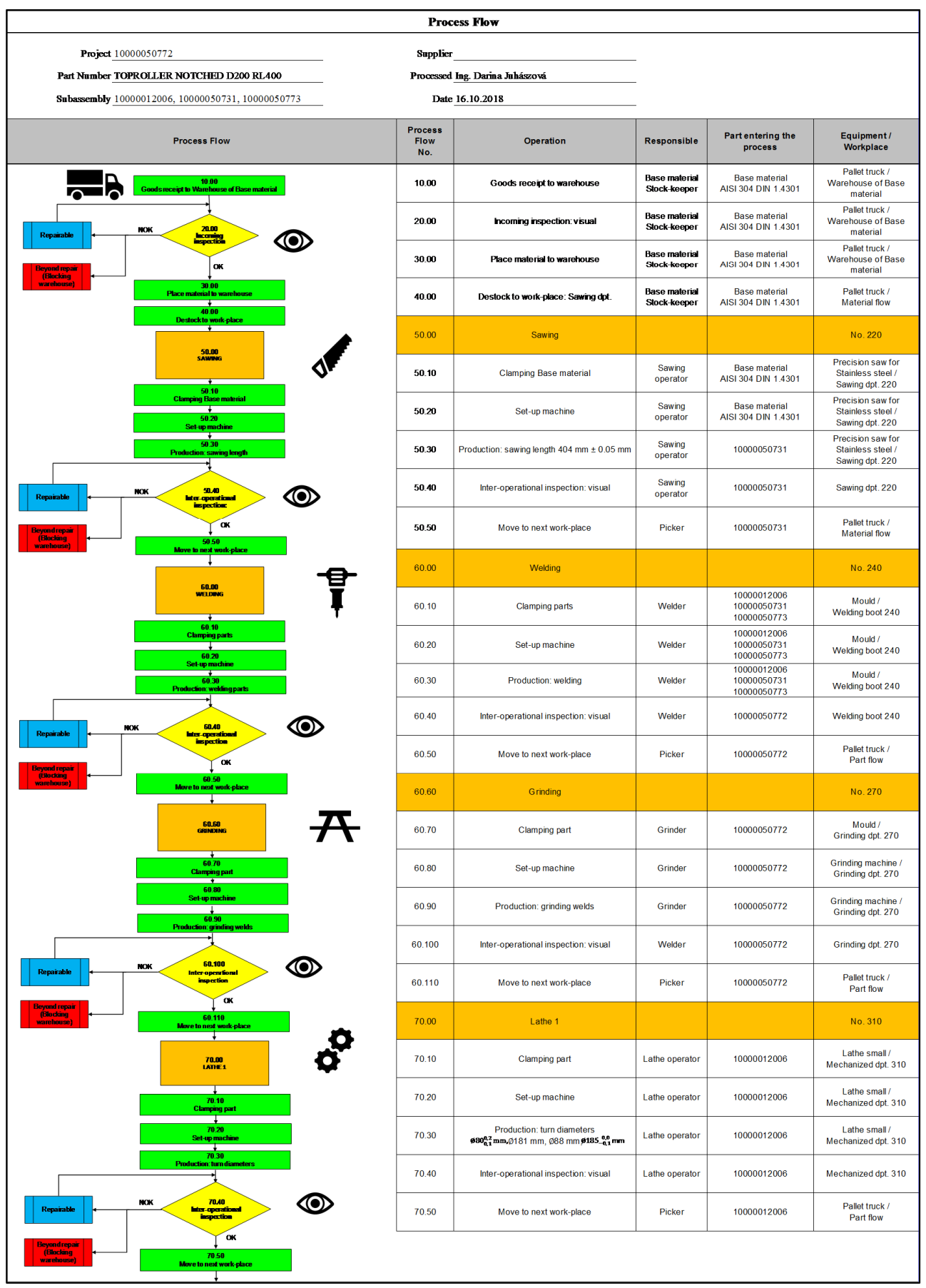

Figure 1 - Process Flow Chart for Production Stainless Steel Roller 


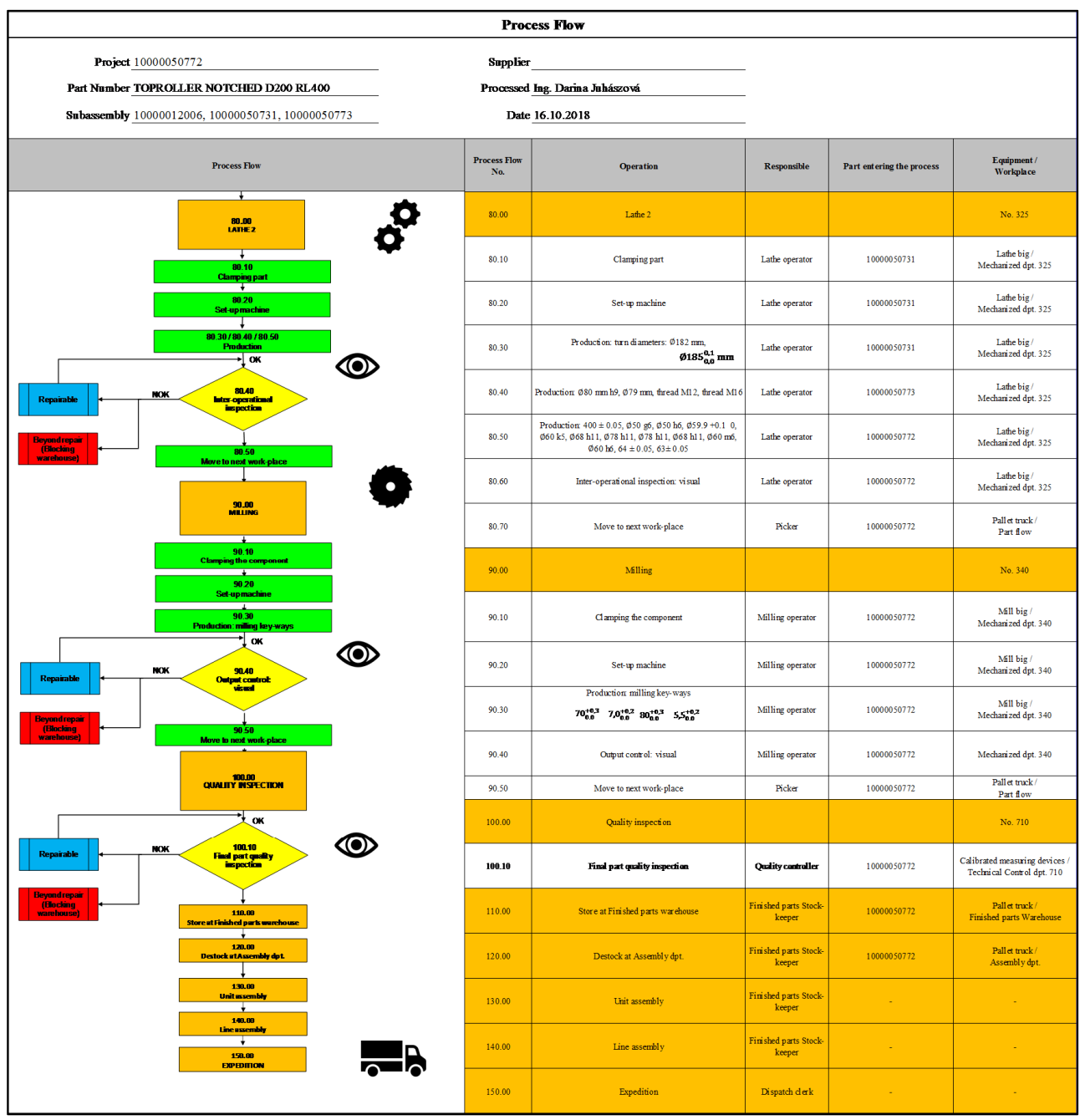

Figure 2 - Process Flow Chart for Stainless Steel Roller-Continuation

\subsection{Preparation for SPC Implementation}

Before the SPC implementation, it was necessary to identify processes and monitored variables. Processes: cutting raw material, lathe operation.

Observed variables: tube length (tolerance \pm 0.05$)$; precise shaft diameter $(\phi 50$ h6); total runout $(0.05 \mathrm{~mm})$ and straightness $(0.05 \mathrm{~mm})$. Furthermore, it was necessary to ensure the conditions for SPC, i.e. steadiness of all known effects: temperature in the range of $16^{\circ} \mathrm{C}-20^{\circ} \mathrm{C}$; air humidity $50 \%-60 \%$, and material quality according to DIN 1.4301 (AISI 304) austenitic chrome-nickel steel.

Subsequently, MSA was performed, while all measurements were made by calibrated measuring devices and by experienced and trained personnel of the Technical Control department. Measurement system analysis processed in (QI- 
Macros, 2018) showed that the influence of the measurement process is less than $10 \%$.

Period of data collection is January 2017 - November 2017. A number of tube length measurements is 50. A number of diameter measurements: 150, with a range of subgroup 3 and the number of subgroups are 50. In the case study, the summaries of the short run and small mixed batch control charts applications are present:

- $X_{i}, m R$ control chart for cutting precise tube length $(404 \pm 0.05,604 \pm 0.05$, $804 \pm 0.05)$

- $\bar{X}, R$ for measuring precise shaft diameter $(\phi 50 \mathrm{~h} 6)$.

Hotelling T2 control chart for a mutual combination values for straightness and total runout $(0.050 \mathrm{~mm}$ and $0.050 \mathrm{~mm})$.

\subsection{Control Chart $X_{i}, m R$}

Cutting (vertical separation) of three types of stainless steel tubes to exact length (Tab. 1) was monitored for eleven months. Fifty data were obtained which, after clustering and transformation to a single scale, were recorded in $X i$, control chart (Fig. 3) and $m R$ control chart Fig. 4. The tubes vary in length; their common sign is material and tolerance. Data originates from a normal distribution processed in (QI-Macros, 2018).

Table 1 - Dimensions of 3 Types of Monitored Rollers

\begin{tabular}{|l|c|c|c|}
\hline Rollertype & Shaft length $[\mathrm{mm}]$ & Tube diameter[mm] & Tube length[mm] \\
\hline 400 & 941 & 182 & $404 \pm 0.05$ \\
\hline 600 & 1,141 & 182 & $604 \pm 0.05$ \\
\hline 800 & 1,341 & 160 & $804 \pm 0.05$ \\
\hline
\end{tabular}




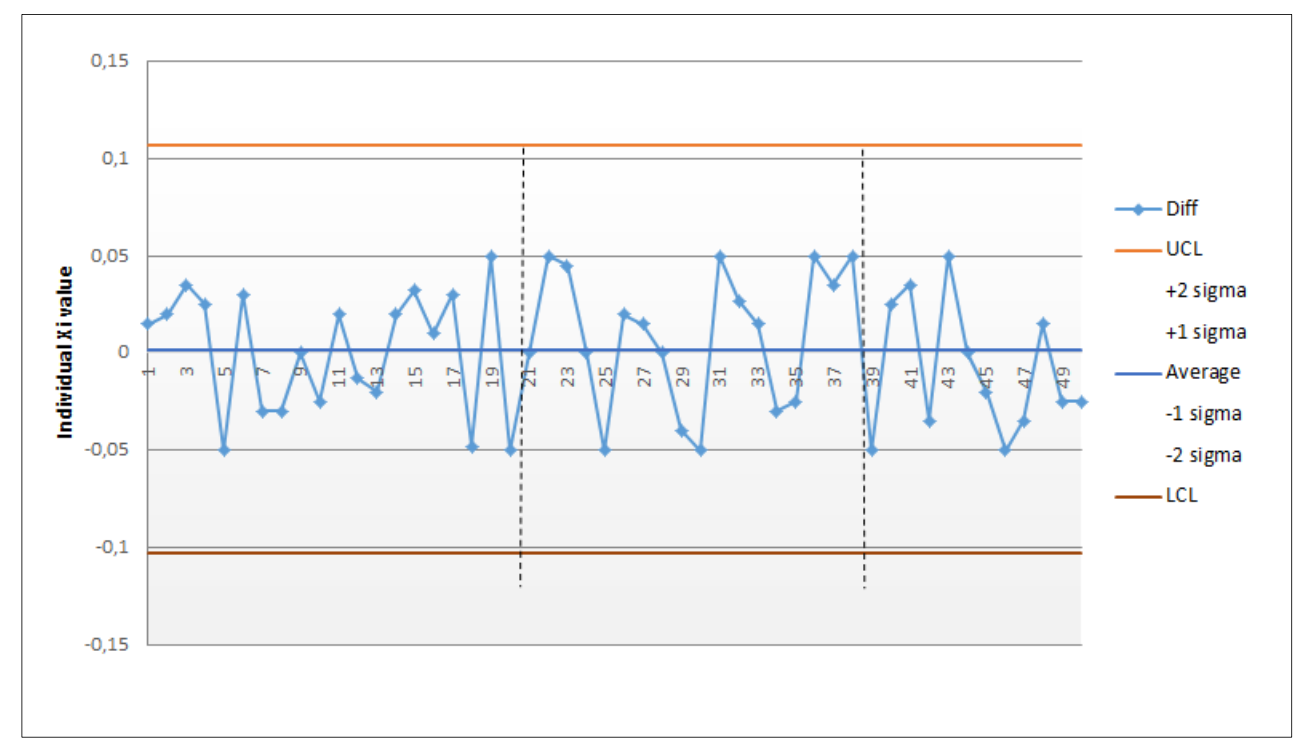

Figure 3 - Control Chart for Transformed Individual Values $X_{i}, m R$ for the Process of Vertical Steel Cutting

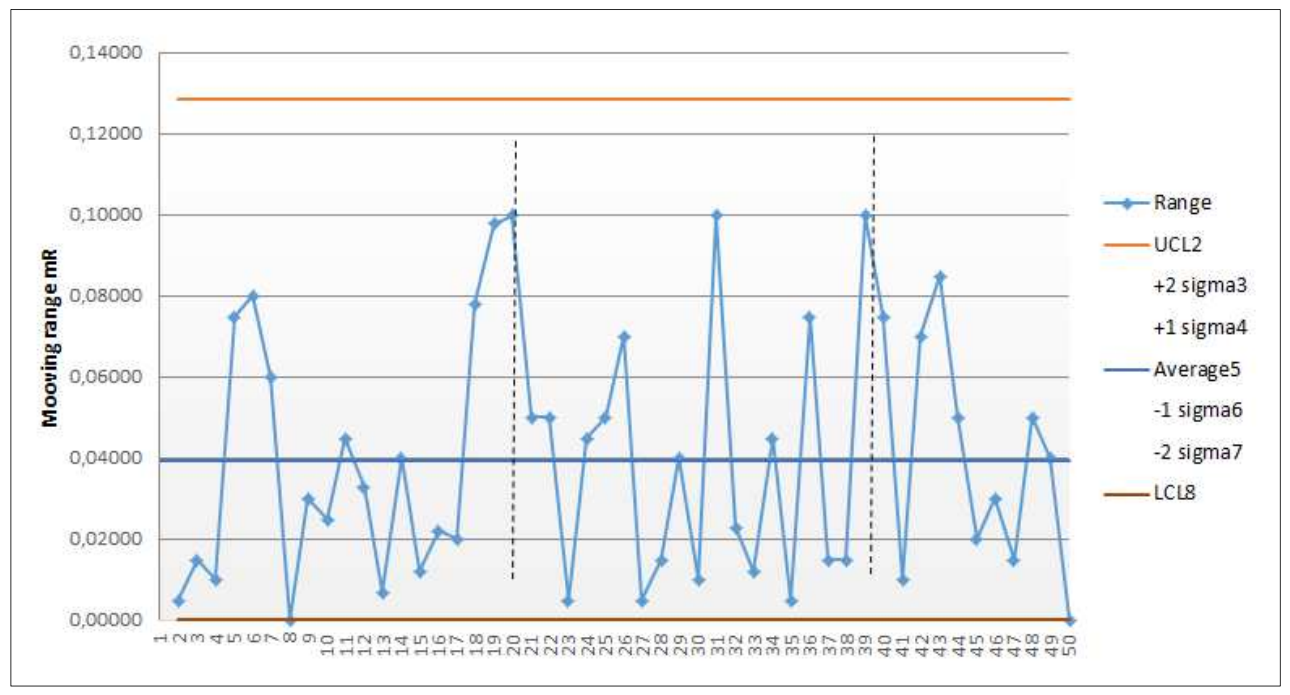

Figure 4 - Control Chart for Moving Range mR For the Process of Vertical Steel Cutting

Summary: Data in a control chart for individual values $X_{i}, m R$ are centered, located within the control zone, and deviating measurements were not detected.

In the moving range chart, $m R$ has used ranges between consecutive values. The control zone was not exceeded. The process is stable. 


\subsection{Control Chart $\bar{X}, R$}

Lathe operation of stainless steel roller diameters has been monitored for 11 months. Overall 150 data were gathered and grouped into 50 selections, each of which contained 3 pieces. The data were recorded in $\bar{X}, R$ control chart (Fig. 5). The rolls vary in length and tube diameter. Their common sign is material and shaft diameter $\phi 50 h 6$.

Standard probability plot processed in (QI-Macros, 2018) shows that the data are from a normal distribution.

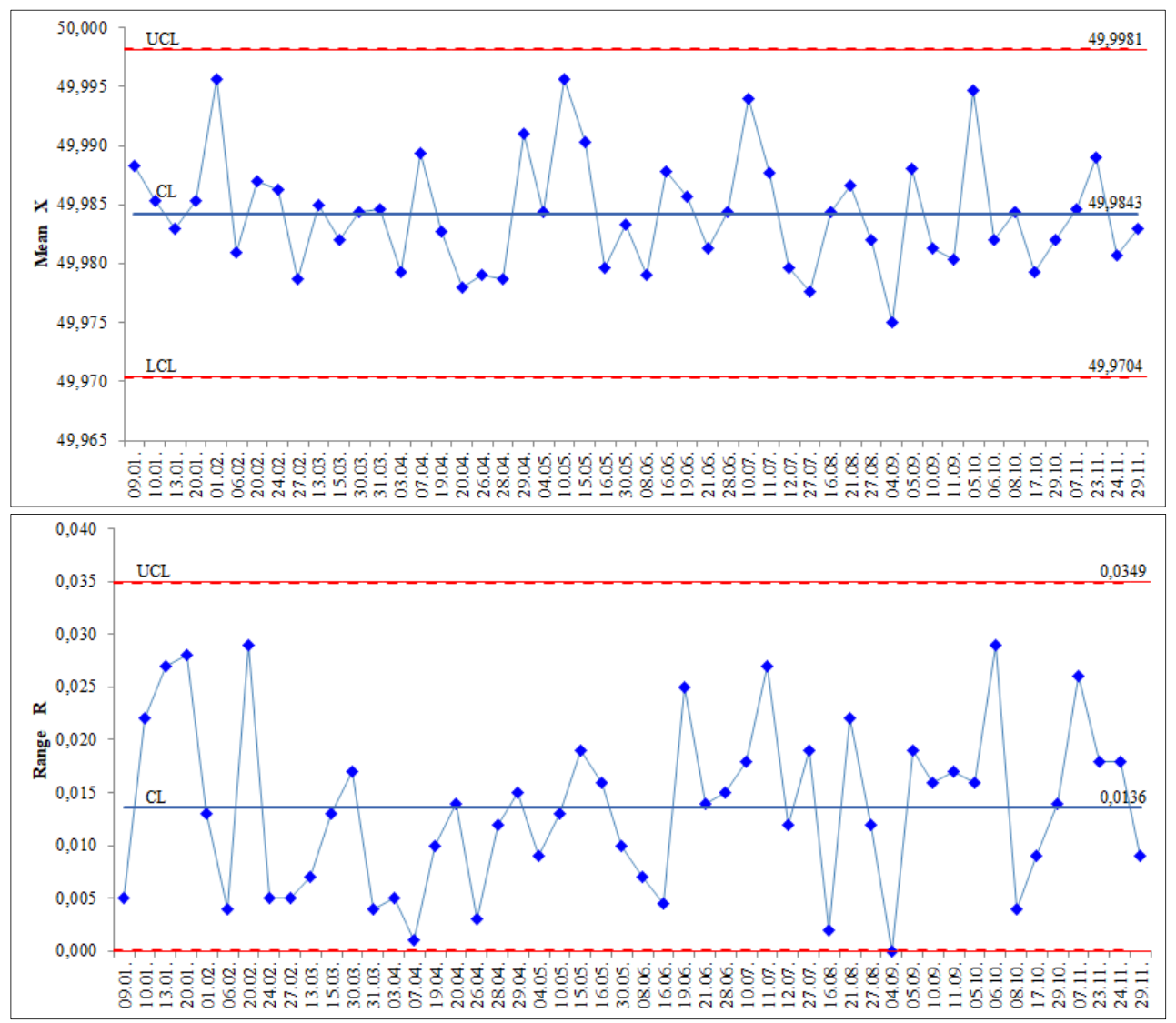

Figure 5 - Control Chart $\bar{X}, R$ for the Process of Precise Shaft Diameter $\Phi 50$ h6

Summary: Through $\bar{X}, R$ it has been verified that production of all three types of rollers $(400,600$ and $800 \mathrm{~mm})$ is considered as statistically under control, all values of monitored characteristics are within the control limits. 


\subsection{Hotelling T2 Control Chart}

Similar to the $X_{i}, m R$ chart, the Hotelling T2 chart evaluates the covariances of the ranges between each of the two measures and the covariances of the actual data points.

For the mutual combination of values, preliminarily ${ }^{1}$ the results from measurements of straightness and total runout were recorded in the Hotelling T2 control chart (Fig. 6, Fig. 7). Standard probability plot processed in (QI-Macros, 2018) shows that the data are from a normal distribution.

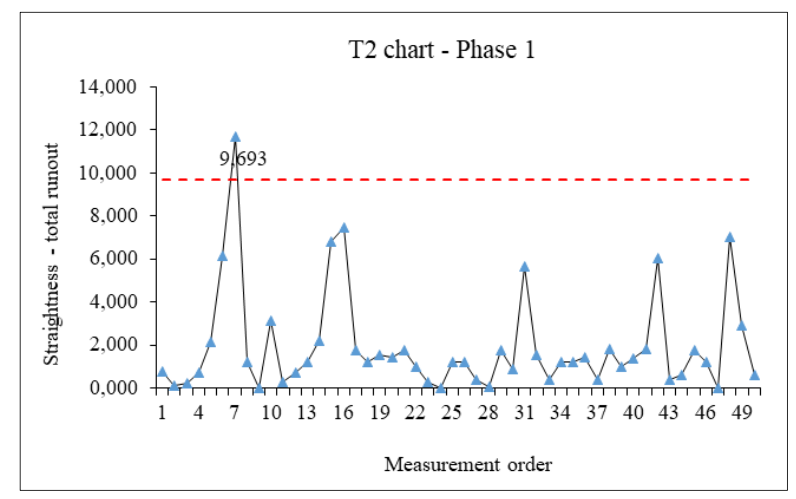

Figure 6-Phase 1 Hotelling T2 Control Chart

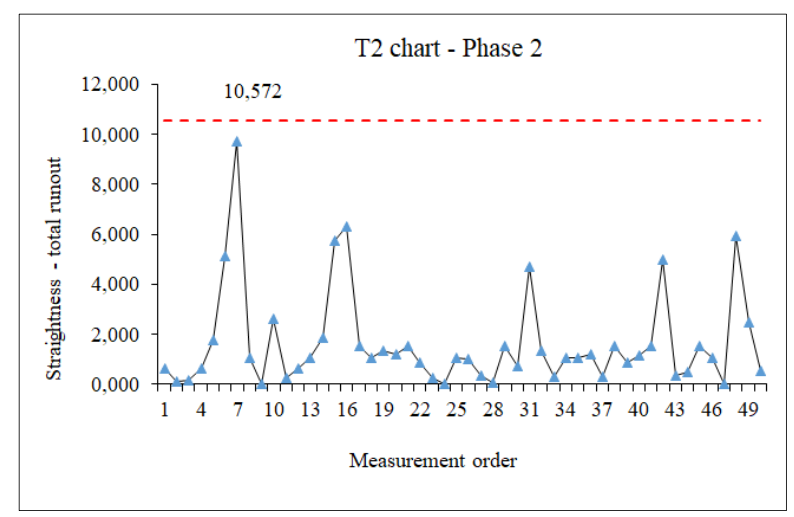

Figure 7 - Phase 2 Hotelling T2 Control Chart

Summary: The 1st chart (Phase 1) shows an outlying measurement, which was detected as measurement No. 7. The measured value of straightness and total runout is higher than the specification limit $(0.071 \mathrm{~mm}-0.065 \mathrm{~mm}$ towards $0.050 \mathrm{~mm}-0.050 \mathrm{~mm}$ ).

\footnotetext{
${ }^{1}$ because further measurements are not yet available.
} 


\section{CONCLUSION}

Research in the area of short run and small mixed batches production is based on a preliminary literature review and focuses on preparing the implementation of the SPC in an organization producing bakery equipment. As part of this preparatory phase of the SPC, the process of cutting and lathe operations were monitored. $\bar{X}, R ; X_{i}, m R$ and Hotelling $\mathrm{T} 2$ shows that both processes are stable, but according to the Hoteling T2 control chart and the reports of experienced operators, it can be assumed that the processes are significantly affected by characteristics of the current machine state, by set-up the machines, and of what level experiences have operators.

Future research opportunity we see in the continuation of the measurements so that the same number of measurements is ensured for both separately monitored processes. Data transformation into a single scale, more detail use of Hotelling statistics, inspection of downtimes, searching for possibilities to reduce production completeness (work-in-progress) and optimizing the use of production facilities using Lean Six Sigma tools.

\section{ACKNOWLEDGEMENTS}

This paper was developed within the project VEGA 1/0904/16 "The utilization of processes capability and performance, and products dimensional tolerances in the management of material consumption, and related economic, energy and environmental consequences (MINIMAX-3E)" supported by The Ministry of Education, Science, Research and Sport of the Slovak Republic.

\section{REFERENCES}

Brännmark, M., Langstrand, J., Johansson, S., Halvarsson, A., Abrahamsson, L. and Winkel, J., 2012. Researching Lean: Methodological Implications of Loose Definitions. Quality Innovation Prosperity, 16(2), pp. 35-48. https://doi.org/10.12776/qip.v16i2.67.

Cullen, J., 1987. The Use of Statistical Process Control in One - Off and Small Batch Production. Chicago, s.n.

Foster, G., 1988. Implementing SPC in Low Volume Manufacturing. ASQC Annual Quality Congress, Dallas TX, 42(0), pp. 261-267.

ISO, 2017. International Standard 7870-8: Control charts - Part 8: Charting Techniques for Short Runs and Small Mixed Batches. Geneva: ISO.

Jarošová, E. and Noskievičová, D., 2015. More Advanced Methods of Statistical Process Control. Prague: Grada Publishing.

Juhászová, D. and Čička, M., 2018. Measurements and Data Processing in Short Run Small Batch Mixed Production. In: Faculty of Materials, Metallurgy and 
Recycling Technical University of Košice, Metallurgy Junior 2018 Proceedings. Herl'any, Slovakia, 10-11 May 2018. Košice: Technical University of Košice.

Juhászová, D. and Zgodavová, K., 2017. Short Run Small Batch Mixed Production Statistical Process Control. In: Faculty of Materials, Metallurgy and Recycling Technical University of Košice, Metallurgy Junior 2017 Proceedings. Košice: Technical University of Košice.

Lee, W. and Lau, H., 1999. Factory on Demand: The Shaping of an Agile Production Network. International Journal of Agile Management Systems, 2(1), pp. 83-87. https://doi.org/10.1108/14654659910280901.

Nuget, B., 1990. SPC in Short Run Processes Productivity. Dayton: Quality Systems.

QI-Macros, 2018. QI Macros SPC Software for Excel. [online] Denver: KnowWare International. Available at: < https://www.qimacros.com/> [Accessed 26 November 2018].

Tošenovský, F., 2010. A Mathematical Model for Process Cycle. Quality Innovation Prosperity, 14(1-2), pp. 64-71.

Zgodavova, K. 1995. Contribution toward the Total Quality Management of Piece and Small Batch Production. Ph. D. Technical University of Košice.

\section{ABOUT THE AUTHOR}

Ing. Darina Juhászová - PhD student at the Technical University of Kosice, Faculty of Materials, Metallurgy and Recycling, Institute of Materials and Quality Engineering. Her work sphere is dedicated to quality and application of Six Sigma tools in both small and large scale production. Her research interests are related to control charts and optimization of engineering production through their use. Author's ORCID: https://orcid.org/0000-0003-4273-5358. 